\title{
Monte Carlo Simulation in Prediction of Periodical Sales
}

\author{
Subhan Hartanto, Andysah Putera Utama Siahaan \\ Faculty of Science and Technology, Universitas Pembangunan Panca Budi, Medan, Indonesia \\ Email: subhanhartanto@dosen.pancabudi.ac.id, andiesiahaan@gmail.com
}

\begin{abstract}
Sales prediction is a budget that contains estimates about the activities of a company within a specified period to come and contains estimates of the state or financial position of the company in the future. The outcome of a sales prediction is a statement or assessment that is quantified against future conditions regarding sales as a technical projection of potential consumer demand for a certain period. However, the estimated results obtained may not be the same as the plan. The Monte Carlo simulation is also known as the Sampling Simulation or the Monte Carlo Sampling technique. Sampling Simulation illustrates the possibility of using sample data in the Monte Carlo method and its probability can be known or estimated. This simulation uses valid data in previous periods. The data is used to predict the possible results that will occur in the coming period. The purpose of this simulation is to estimate the profitability of a company to sell.
\end{abstract}

Key Words: Monte Carlo, prediction, sales, market.

\section{INTRODUCTION:}

The development of information technology causes an increase in problems [1]-[3]. Problems consist of simple and complex. Complex problems require proper handling, resulting in high accuracy. Things can also be solved using the simulation method [4]-[6] Each problem can be modeled and simulated based on the parameters used. This simulation can predict future results without first having to be implemented directly. A model is a representation of an object, object, or idea in a simplified form. Simulation is a quantitative procedure, which describes a simple system. Model development of the system will experience a series of trials to estimate results in certain periods. A simulation model is a model that describes the cause and effect relationship in a system on a computer model. This method can describe behavior that might occur in the real world [7].

Several ways can be done to determine future events. It includes determining the sale of a company. Simulation is one way to predict the company's profits and losses based on income and financial position in the periods that have passed. Monte Carlo is a simulation method that can be used as a prediction method [8]. Several supporting parameters strongly influence the accuracy of the Monte Carlo simulation results [9]. This simulation can be a reliable tool for a company leader in analyzing risks, advantages, and disadvantages of the company being led. Monte Carlo simulation results can help improve the quality of products sold. With the growing ability of computers and software, this Monte Carlo simulation should be more widely used by business people. By using this method, the company can anticipate losses that will occur in the future and can correct the company's weaknesses caused by several factors.

\section{THEORIES:}

The Monte Carlo method is the basis for all algorithms of the simulation method based on the thought of solving a problem to get better results by giving as much value as possible to get higher accuracy. For example, to obtain a level of accuracy up to 0.01 , it is necessary to generate a value of 10000 , etc. This method adheres to a free programming system without being too much bound by specific rules or rules. According to Wikipedia, the Monte Carlo method is a computational algorithm to simulate various physical and mathematical system behavior. The classic use of this method is to evaluate definite integrals, especially multidimensional integrals with complicated terms and constraints. The Monte Carlo method is essential in computational physics and other applied fields and has applications ranging from esoteric quantum chromodynamics to aerodynamic design. This method has proven to be efficient in solving differential equations of radians field, so this method is used in calculating global illuminations that produce photorealistic images of three-dimensional models, which are applied in video games, architecture, design, computer-generated films, special effects in film, business, economics, and other fields [10].

\subsection{Monte-Carlo Simulation Method}

Monte Carlo Simulation Method is a method for evaluating a deterministic model involving random numbers as one input. This method is often used if the model used is quite complex, non-linear or involves more than a pair of uncertain parameters. A Monte Carlo simulation can involve 10,000 evaluations of a model, a job in the past can only be done by computer software.

Monte Carlo simulation is a method for analyzing uncertainty propagation, where the aim is to determine how random or error variations affect the sensitivity, performance or reliability of the system being modeled. Monte Carlo simulations are classified as a sampling method because the input is generated randomly from a probability distribution 
for the sampling process of a real population. Therefore, a model must choose an input distribution that is closest to the data they have [11].

\subsection{Monte-Carlo Simulation Method}

The main steps in a Monte Carlo simulation are as follows:

1. Defining the probability distribution that is known for specific data obtained from data collection in the past. Besides using past data, determining the probability distribution can also come from a normal distribution and so on. It depends on the nature of the observed. Variable variables that are used in the simulation must be arranged for the probability distribution.

2. Convert the probability distribution into the form of cumulative frequency. This cumulative probability distribution will be used as the basis for the grouping of interval intervals from random numbers.

3. Run the simulation process using random numbers. Random numbers are categorized according to the cumulative probability distribution range of the variables used in the simulation. Uncertain factors often use random numbers to describe the actual conditions. The sequence of simulation processes involving random numbers will give an overview of the actual variation. There are many ways to get random numbers, namely by using tables of random numbers, calculators, computers, and so on.

4. Analysis carried out from simulation output as input for alternatives problem solving and policy making. The management can evaluate the conditions that are happening with the simulation results.

\section{METHODOLOGY:}

Monte Carlo simulation has a stochastic nature which means that this method is based on the use of random numbers and the possibility to identify a problem. The method was previously used to solve quantitative problems with physical processes. The following table is the data that will be used for testing the Monte Carlo simulations.

Table 1. Initial Data

\begin{tabular}{|c|c|}
\hline Demand & Freqency \\
\hline 0 & 20 \\
\hline 1 & 40 \\
\hline 2 & 20 \\
\hline 3 & 10 \\
\hline 4 & 10 \\
\hline
\end{tabular}

Table 1 illustrates that there are five types of goods demand with a specific frequency. The demand as much as 0 and 4 will have a frequency of 20. The demand as much as 1 have a frequency of 40 . The demand as much as 3 and 4 have a frequency of 10. From that data, requests as much as 1 have the most common opportunities from data processing. It means that this number has the highest probability.

\section{RESULT AND DISCUSSION:}

\subsection{Probability and Commulative Probability}

Before determining the results of the Monte Carlo simulation, there are steps to be taken, namely determining the probability and cumulative distribution. In the distribution of sales of goods can be determined the probability distribution and cumulative distribution. The following equation is the formula used to determine distribution.

$$
P=\frac{F}{T F}
$$

Where:

$$
\begin{array}{ll}
\mathrm{P} & =\text { Probability } \\
\mathrm{F} & =\text { Frequency } \\
\mathrm{TF} & =\text { Total Frequency }
\end{array}
$$

By using the previous data, each probability and cumulative probability value can be determined as illustrated below.

Total Frequency $\quad=20+40+20+10+10$

$$
=100
$$


Probability of Demand $0=20 / 100=0,2$

Probability of Demand $1=40 / 100=0,4$

Probability of Demand $2=20 / 100=0,2$

Probability of Demand 3 $=10 / 100=0,1$

Probability of Demand $4=10 / 100=0,1$

Commulative Probability $0=0,2$

Commulative Probability $1=0,2+0,4=0,6$

Commulative Probability $2=0,6+0,2=0,8$

Commulative Probability $3=0,8+0,1=0,9$

Commulative Probability $4=0,9+0,1=1$

Table 2. Probability and Probability Commulative value

\begin{tabular}{|c|c|c|c|}
\hline Demand & Freqency & Probability & C. Probability \\
\hline 0 & 20 & 0,2 & 0,2 \\
\hline 1 & 40 & 0,4 & 0,6 \\
\hline 2 & 20 & 0,2 & 0,8 \\
\hline 3 & 10 & 0,1 & 0,9 \\
\hline 4 & 10 & 0,1 & 1 \\
\hline
\end{tabular}

Table 2 describes the results obtained from the entire data in Table 1. The next step is to determine random numbers with intervals based on cumulative probability results. Table 3 describes the possible random numbers for each request.

Table 3. Possible random numbers appear

\begin{tabular}{|c|c|c|c|c|}
\hline Demand & Freqency & Probability & C. Probability & Random \\
\hline 0 & 20 & 0,2 & 0,2 & $0-20$ \\
\hline 1 & 40 & 0,4 & 0,6 & $21-60$ \\
\hline 2 & 20 & 0,2 & 0,8 & $61-80$ \\
\hline 3 & 10 & 0,1 & 0,9 & $81-90$ \\
\hline 4 & 10 & 0,1 & 1 & $91-100$ \\
\hline
\end{tabular}

\subsection{Simulation Test}

This section will be tested for simulations to determine the level of sales of goods in the future. Table 4 is an example of random data that has been generated to test a Monte Carlo simulation.

Table 4. Data test

\begin{tabular}{|c|c|c|c|}
\hline Period & Random & Demand & Price \\
\hline 1 & 17 & 0 & - \\
\hline 2 & 74 & 2 & 400.000 \\
\hline 3 & 21 & 1 & 200.000 \\
\hline 4 & 40 & 1 & 200.000 \\
\hline 5 & 10 & 0 & - \\
\hline 6 & 1 & 0 & - \\
\hline 7 & 24 & 1 & - \\
\hline 8 & 4 & 0 & - \\
\hline 9 & 10 & 0 & - \\
\hline 10 & 17 & 0 & 400.000 \\
\hline 11 & 19 & 0 & 400.000 \\
\hline 12 & 65 & 2 & 200.000 \\
\hline 13 & 73 & 2 & 400.000 \\
\hline 14 & 60 & 1 & \\
\hline 15 & 78 & 2 & \\
\hline
\end{tabular}


Random of period $1=17$

Demand in Commulative Probability $=0,2$

Demand $\quad=0$

Income $\quad=0 * 200000=0$

Random of period $2=74$

Demand in Commulative Probability $=0,8$

Demand $\quad=2$

Income $\quad=2 * 200000=400000$

Random of period $3=21$

Demand in Commulative Probability $=0,6$

Demand $\quad=1$

Income $\quad=1 * 200000=200000$

Random of period $4=40$

Demand in Commulative Probability $=0,6$

Demand $\quad=1$

Income $\quad=1 * 200000=200000$

Random of period $5=10$

Demand in Commulative Probability $=0,2$

Demand $\quad=0$

Income $\quad=0 * 200000=0$

Random of period $6=1$

Demand in Commulative Probability $=0,2$

Demand $\quad=0$

Income $\quad=0 * 200000=0$

Random of period $7=24$

Demand in Commulative Probability $=0,6$

Demand $\quad=1$

Income $\quad=1 * 200000=200000$

Random of period $8=4$

Demand in Commulative Probability $=0,2$

Demand $\quad=0$

Income $\quad=0 * 200000=0$

Random of period $9=10$

Demand in Commulative Probability $=0,2$

Demand $\quad=0$

Income $=\quad 0 * 200000=0$

Random of period $10=17$

Demand in Commulative Probability $=0,2$

Demand $\quad=0$

Income $\quad=0 * 200000=0$

Random of period $11=19$

Demand in Commulative Probability $=0,2$

Demand $\quad=0$

Income $\quad=0 * 200000=0$

Random of period $12=65$

Demand in Commulative Probability $=0,8$

Demand $=2$

Income $\quad=2 * 200000=400000$ 
Random of period $13=73$

Demand in Commulative Probability $=0,8$

Demand $\quad=2$

Income $\quad=2 * 200000=400000$

Random of period $14=60$

Demand in Commulative Probability $=0,6$

Demand $\quad=1$

Income $\quad=1 * 200000=200000$

Random of period $15=78$

Demand in Commulative Probability $=0,8$

Demand $=2$

Income $\quad=2 * 200000=400000$

Total Demand $\quad=12$

Average Demand $\quad=0,8$

Total Income $\quad=2400000$

Average Income $\quad=160000$

\section{CONCLUSION:}

Monte Carlo simulations can help businesses to evaluate companies. Simulation of demand for goods using the Monte Carlo method is very important in increasing productivity both in sales and the ability of employees to understand the goods demand system. The design of the simulation with the Monte Carlo method can facilitate the search for problems in the real system and learning complexly to understand the goods demand system.

\section{REFERENCES:}

1. H. M. Ritonga, A. P. U. Siahaan, and Suginam, "Marketing Strategy through Markov Optimization to Predict Sales on Specific Periods," Int. J. Innov. Res. Multidiscip. F., vol. 3, no. 8, pp. 184-190, 2017.

2. L. Marlina, A. P. U. Siahaan, H. Kurniawan, and I. Sulistianingsih, "Data Compression Using Elias Delta Code," Int. J. Recent Trends Eng. Res., vol. 3, no. 8, pp. 210-217, Aug. 2017.

3. H. A. Hasibuan, R. B. Purba, and A. P. U. Siahaan, "Productivity Assessment (Performance, Motivation, and Job Training) using Profile Matching," Int. J. Econ. Manag. Stud., vol. 3, no. 6, pp. 73-77, 2016.

4. I. Sumartono, A. P. U. Siahaan, and Arpan, "Base64 Character Encoding and Decoding Modeling," Int. J. Recent Trends Eng. Res., vol. 2, no. 12, pp. 63-68, 2016.

5. A. Putera Utama Siahaan, M. Mesran, and I. Solihin, "Implementation of Super Playfair in Messaging," in Proceedings of the Joint Workshop KO2PI and The 1st International Conference on Advance \& Scientific Innovation, 2018.

6. A. P. U. Siahaan, Mesran, R. Rahim, and D. Siregar, "K-Gram As A Determinant Of Plagiarism Level In RabinKarp Algorithm," Int. J. Sci. Technol. Res., vol. 6, no. 7, pp. 350-353, 2017.

7. M. Hoesli, E. Jani, and A. Bender, "Monte Carlo simulations for real estate valuation," J. Prop. Invest. Financ., vol. 24, no. 2, pp. 102-122, Mar. 2006.

8. A. Prakash, S. K. Jha, and R. Prasad Mohanty, "Scenario planning for service quality: a Monte Carlo simulation study," J. Strateg. Manag., vol. 5, no. 3, pp. 331-352, Aug. 2012.

9. M. Nedjalkov and P. Vitanov, "MONTE CARLO TECHNIQUE FOR SIMULATION OF HIGH ENERGY ELECTRONS," COMPEL - Int. J. Comput. Math. Electr. Electron. Eng., vol. 10, no. 4, pp. 525-530, Apr. 1991.

10. Ansyahh, "Simulasi Monte Carlo," 2013. [Online]. Available: http://ansyahh.blogspot.com/2013/05/simulasimonte-carlo.html. [Accessed: 03-Oct-2018].

11. R. Y. Rubinstein, Simulation and the Monte Carlo Method. New York, NY, USA: John Wiley \& Sons, Inc., 1981. 